\title{
In Situ Synthesis of Poly(methyl methacrylate)/SiO 2 Hybrid Nanocomposites via “Grafting Onto" Strategy Based on UV Irradiation in the Presence of Iron Aqueous Solution
}

\author{
Hong Zhang, Chao Li, Jinshan Guo, Limin Zang, and Jiahe Luo \\ Institute of Polymer Science and Engineering, College of Chemistry and Chemical Engineering, Lanzhou University, \\ 222 Tianshui South Road, Gansu 730000, China \\ Correspondence should be addressed to Jinshan Guo, gjs@lzu.edu.cn
}

Received 11 March 2011; Revised 6 May 2011; Accepted 1 June 2011

Academic Editor: Hai-Sheng Qian

Copyright (c) 2012 Hong Zhang et al. This is an open access article distributed under the Creative Commons Attribution License, which permits unrestricted use, distribution, and reproduction in any medium, provided the original work is properly cited.

Poly(methyl methacrylate)/SiO $2\left(\mathrm{PMMA} / \mathrm{SiO}_{2}\right)$ hybrid composites were prepared via "grafting onto" strategy based on UV irradiation in the presence of iron aqueous solution. Two steps were used to graft polymethyl methacrylate (PMMA) onto the surface of nanosilica, anchoring 3-(methacryloxy) propyl trimethoxysilane (MPTS) onto the surface of nanosilica to modify it with double bonds, and then grafting PMMA onto the surface of nanosilica with $\mathrm{FeCl}_{3}$ as photoinitiator. The products were characterized by FT-IR, TGA, TEM, DLS, and XPS. The results showed that it is easy to graft PMMA onto the surface of nanosilica under UV irradiation, and the hybrid particles are monodisperse and have core-shell structure with nanosilica as the core and PMMA layers as the shell. Furthermore, the products initiated by $\mathrm{FeCl}_{3}$ have higher monomer conversion, percent grafting, and better monodispersion compared with the products initiated by traditional photoinitiator such as 2-hydroxy-4-(2-hydroxyethoxy)-2methyl-propiophenone (Irgacure 2959).

\section{Introduction}

Recently, the polymer/inorganic nanocomposites have gained great attention [1-5] because of their potential applications in many surface-based technologies such as composite materials, biomaterials, adhesion and wetting, molecular recognition, microfluidics, chemical sensing, and organic synthesis [6-12]. What is more is that the polymer/ inorganic nanocomposites have excellent properties, such as mechanical properties, thermal stability, and flame retardance, gas barrier properties, and biodegradation and abrasion resistance [13-16]. The polymer/inorganic hybrid materials are generally prepared by surface modification of the inorganic particles. At present, there are many approaches for modifying solid surfaces with polymers, including physisorption, covalent attachment, and electrostatic adsorption [17]. Physisorption is relatively an easy way, but it suffers from solvolytic and thermal instabilities due to the absence of stable covalent bonds on the surface [18]. There are three approaches to covalently graft polymer chains on the surface of inorganic particles: (1) the "grafting to" method [19, 20], where the end-functionalized polymers react with an appropriate surface; (2) the "grafting from" method [21, 22], where polymer chains are grown from initiator-terminated self-assembled monolayer; (3) the "grafting onto" method [23], where surface copolymerization is through a covalently linked monomer.

UV light has also become a useful tool for initiating polymerization due to its significant advantages [24, 25], and this method has been applied to emulsion polymerization [26, 27]. The polymerization can be easily varied by controlling the emulsifier concentration and the initiator concentration. Furthermore, it could accomplish high efficiency of the polymerization process in a short time even using a small percentage of photoinitiation. In contrast to thermally based applications which usually require elevated temperatures, photopolymerization can also be performed at room temperature and below. This is a striking advantage for both classical polymerization of monofunctional monomers and modern curing applications. Low-molecular-weight organic 


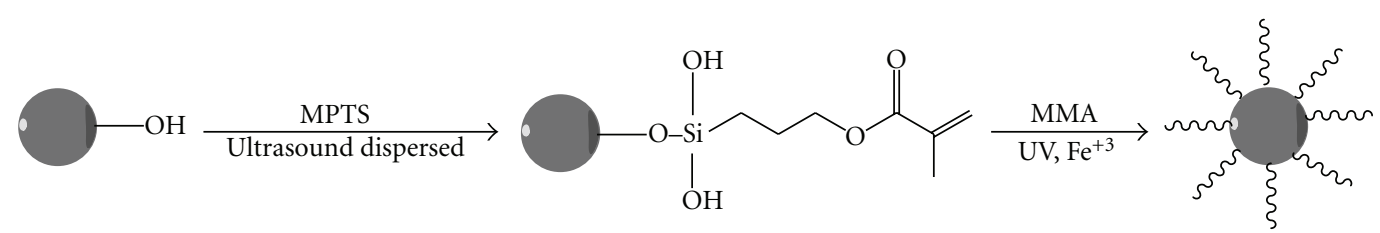

$\mathrm{SiO}_{2}$ $\mathrm{SiO}_{2} @ \mathrm{MPTS}$

$\mathrm{SiO}_{2} @ \mathrm{PMMA}$

SCHEme 1: The grafting polymerization of MMA from the MPTS-modified nanosilica surface.

TABLE 1: Compositions of the PMMA grafting onto silica nanoparticles.

\begin{tabular}{|c|c|c|c|c|c|c|}
\hline Sample & m (SiO $\left.{ }_{2} @ M P T S\right)(g)$ & CTAB (g) & MMA (g) & $\mathrm{FeCl}_{3} \cdot 6 \mathrm{H}_{2} \mathrm{O}(\mathrm{g})$ & Irgacure $2959(\mathrm{~g})$ & $\mathrm{H}_{2} \mathrm{O}(\mathrm{g})$ \\
\hline S-1 & 0.01 & 0.25 & 5.0 & 0.01 & - & 20 \\
\hline S-2 & 0.03 & 0.25 & 5.0 & 0.01 & - & 20 \\
\hline S-3 & 0.05 & 0.25 & 5.0 & 0.01 & - & 20 \\
\hline S-4 & 0.20 & 0.25 & 5.0 & 0.01 & - & 20 \\
\hline S-5 & 0.50 & 0.25 & 5.0 & 0.01 & - & 20 \\
\hline S-6 & 0.05 & 0.25 & 5.0 & - & 0.01 & 20 \\
\hline
\end{tabular}

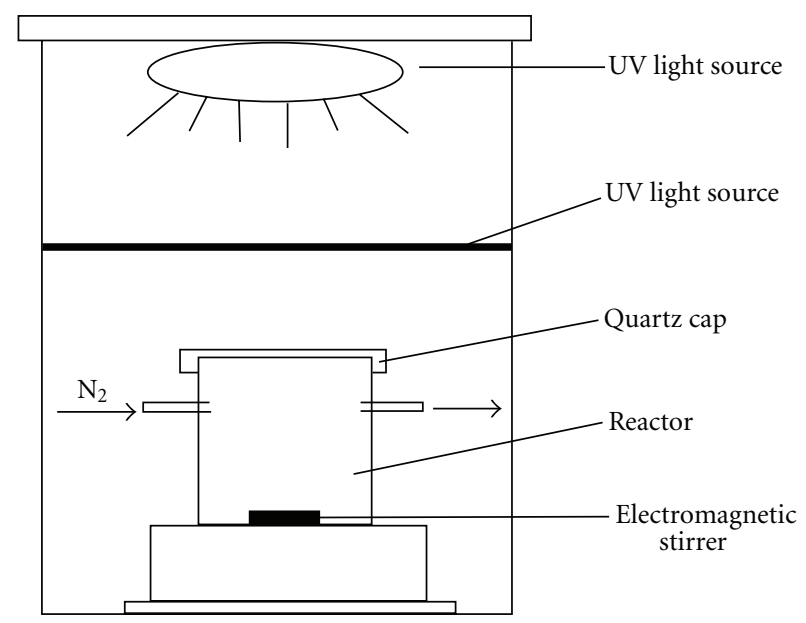

FIGURE 1: A schematic representation of the UV initiated polymerization reacting setup.

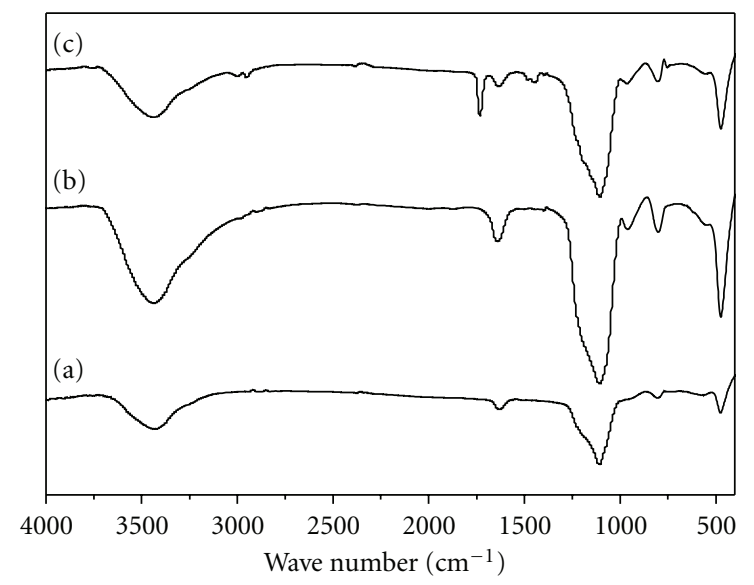

FIGURE 2: FTIR spectra of (a) bare silica particles, (b) $\mathrm{SiO}_{2} @ \mathrm{MPTS}$ particles, and (c) $\mathrm{SiO}_{2} @$ PMMA particles.

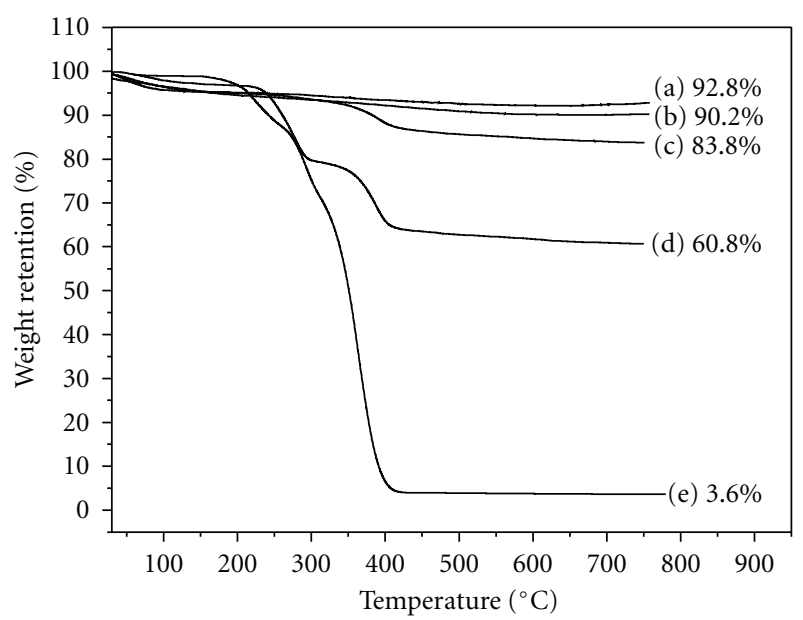

FIgure 3: Thermogravimetric analysis (TGA) of (a) bare silica, (b) $\mathrm{SiO}_{2} @ M P T S$ particles, (c) $\mathrm{SiO}_{2} @ P M M A$ particles (S-5), (d) $\mathrm{SiO}_{2} @ P M M A$ particles (S-4), and (e) $\mathrm{SiO}_{2} @ P M M A$ particles (S-3); TGA was performed in nitrogen at a heating rate of $10^{\circ} \mathrm{C} / \mathrm{min}$.

photoinitiators, however, have many intrinsic disadvantages such as hydrophobicity, odor, and toxicity, which limit the applications of photoinitiation in emulsion polymerization. One possible way to solve this problem is the use of watersoluble inorganic photoinitiators.

In this work, we used $\mathrm{FeCl}_{3}$ as photoinitiator to prepare $\mathrm{PMMA} / \mathrm{SiO}_{2}$ hybrid nanocomposites. The likely mechanism of photoinitiation using $\mathrm{Fe}^{3+}$ as photoinitiator has been reported by Evans et al. [28]. It has been found in our research that it possesses high efficient photoinitiation even though using a small percentage of photoinitiation. Moreover, there are several advantages by using $\mathrm{FeCl}_{3}$ as photoinitiator such as water solublility, nonpollution, and odorlessness. After the polymerization, it could be scoured 


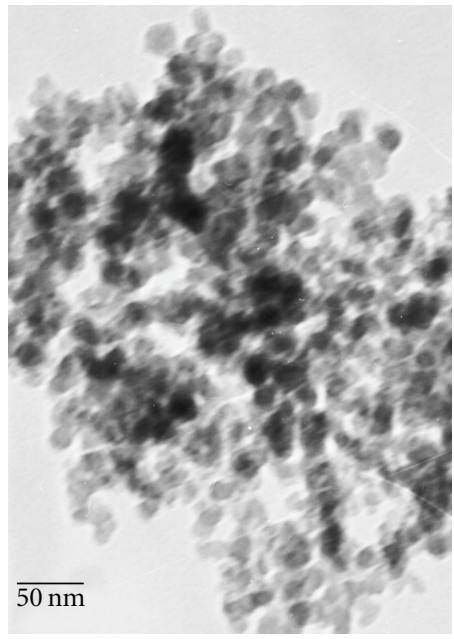

(a)

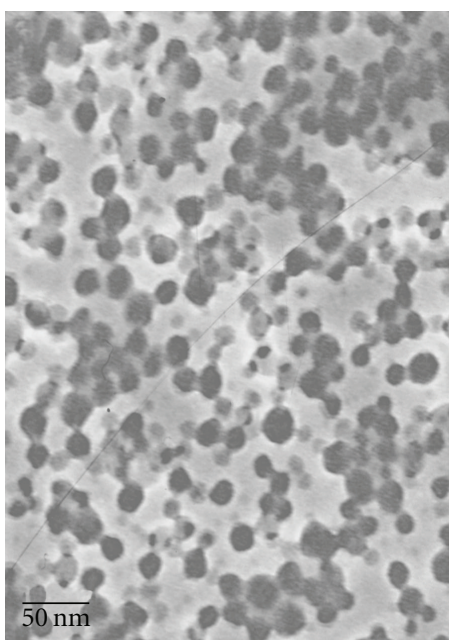

(c)

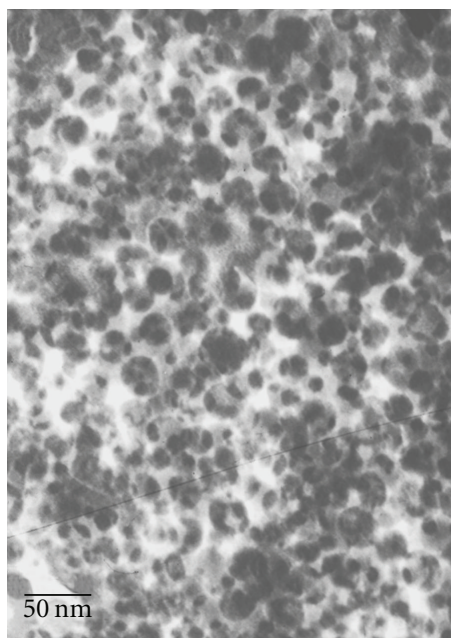

(e)

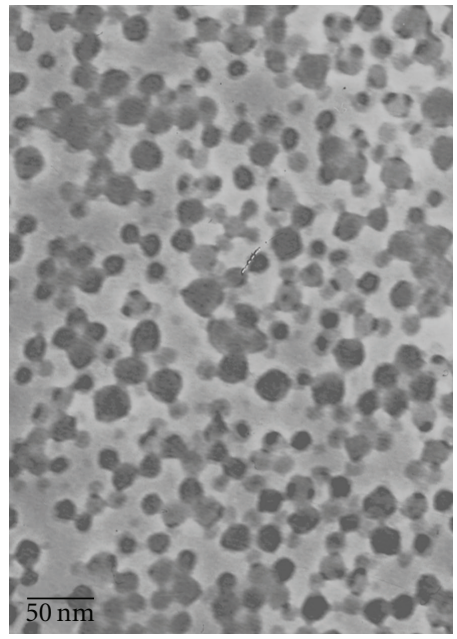

(b)

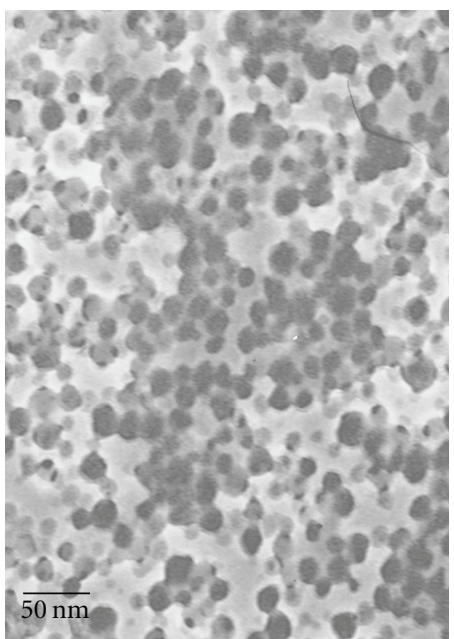

(d)

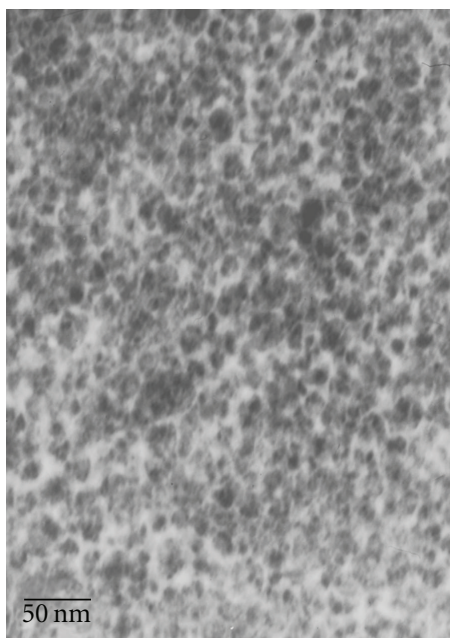

(f)

FIGURE 4: TEM images of (a) bare silica particles, (b) $\mathrm{SiO}_{2} @ P M M A$ particles (S-1), (c) $\mathrm{SiO}_{2} @ P M M A$ particles (S-2), (d) $\mathrm{SiO}_{2} @ \mathrm{PMMA}$ particles (S-3), (e) $\mathrm{SiO}_{2} @$ PMMA particles (S-4), and (f) $\mathrm{SiO}_{2} @ P M M A$ particles (S-5) cast from dilute deionized water. 
TABLE 2: Comparison of UV-initiated polymerization initiated by $\mathrm{FeCl}_{3}$ and Irgacure 2959.

\begin{tabular}{lccccc}
\hline Sample & Particle size $(\mathrm{nm})$ & PDI & Reaction time $(\mathrm{min})$ & ${\text { Conversion }(\%)^{\mathrm{a}}}$ & Grafting $(\%)^{\mathrm{b}}$ \\
\hline S-3 & 32 & 0.289 & 10 & 95.4 & 98.0 \\
S-6 & 27 & 0.352 & 10 & 75.7 & 85.8 \\
\hline
\end{tabular}

${ }^{a}$ Conversion values determined using gravimetric analysis.

${ }^{b}$ Polymer grafting (\%) is calculated from (2).

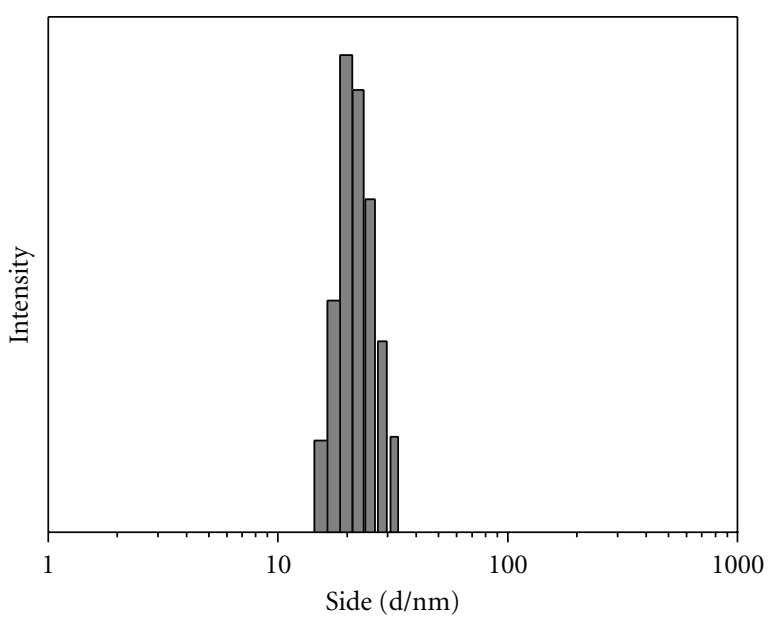

(a)

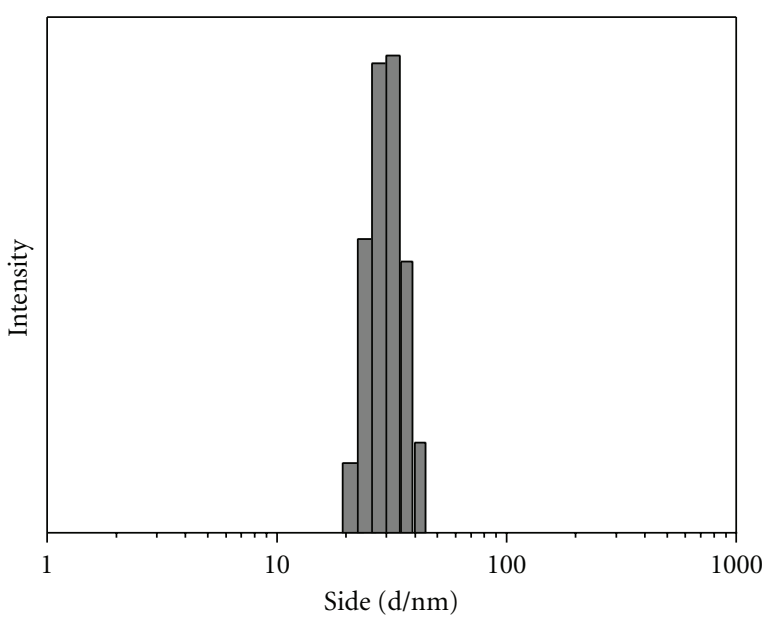

(b)

Figure 5: DLS images of (a) bare silica particles and (b) $\mathrm{SiO}_{2} @$ PMMA particles (S-3).

off easily. Compared to the traditional photoinitiation initiated by Irgacure 2959, the products initiated by $\mathrm{FeCl}_{3}$ have higher monomer conversion, percent grafting, and better monodispersion. Considering the above factors, herein, we describe an effective strategy to prepare $\mathrm{PMMA} / \mathrm{SiO}_{2}$ hybrid composites via "grafting onto" strategy based on UV irradiation in the presence of iron aqueous solution. Nanosilica particles have been surface modified by 3(methacryloxy) propyl trimethoxysilane (MPTS) to possess double bonds, so that methyl methacrylate (MMA) can been grafting onto $\mathrm{SiO}_{2}$ with nanosilica as the core and PMMA as the shell. $\mathrm{FeCl}_{3}$ was used for the photoinitiator

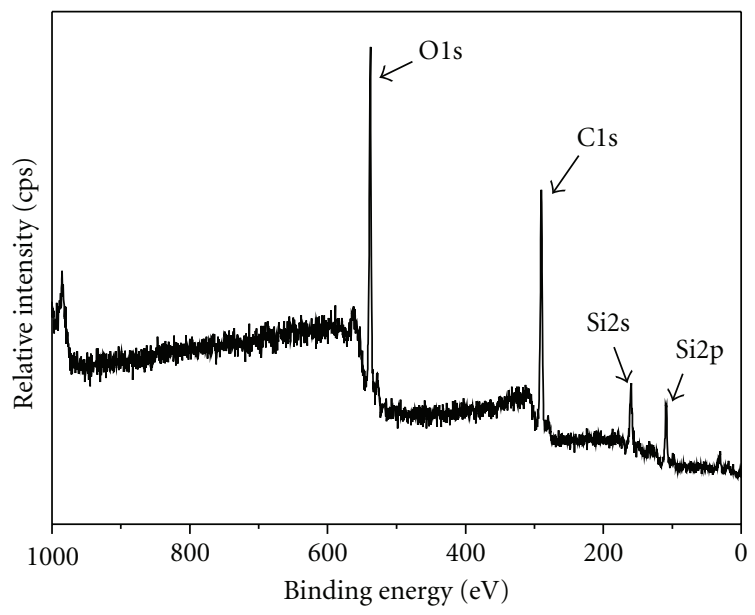

(a)

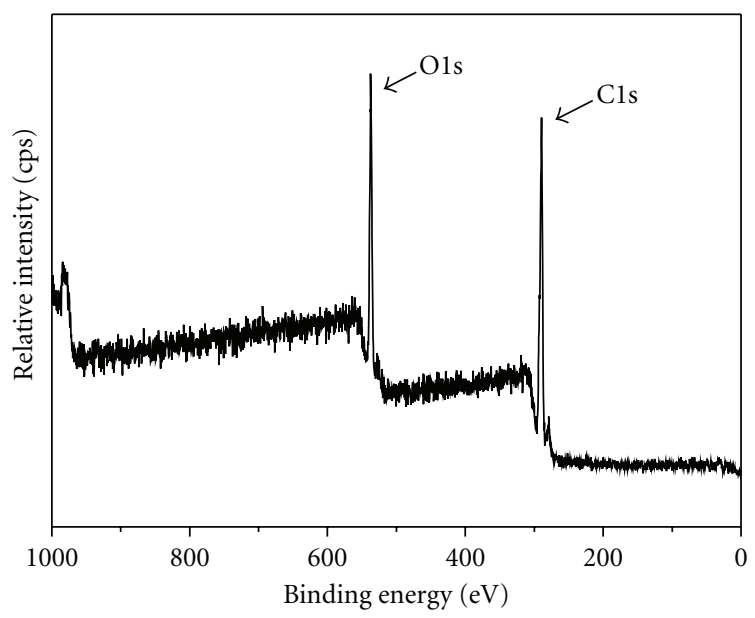

(b)

Figure 6: XPS wide scan for (a) $\mathrm{SiO}_{2} @ M P T S$ particles and (b) $\mathrm{SiO}_{2}$ @PMMA particles (S-3).

under UV irradiation in this process. Scheme 1 shows the overall synthesis route. The products were characterized by FT-IR, TGA, TEM, XPS, and DLS. In addition, different proportions of $\mathrm{SiO}_{2}$ were added to discuss the best condition of preparing $\mathrm{PMMA} / \mathrm{SiO}_{2}$ particles with better monodisperse and uniform morphology.

\section{Experimental Section}

2.1. Materials. The silica having mean particle size of $20 \mathrm{~nm}$ was kindly supplied by Aladdin Chemical Reagent Co., Ltd. 3-(methacryloxy) propyl trimethoxysilane (MPTS) 

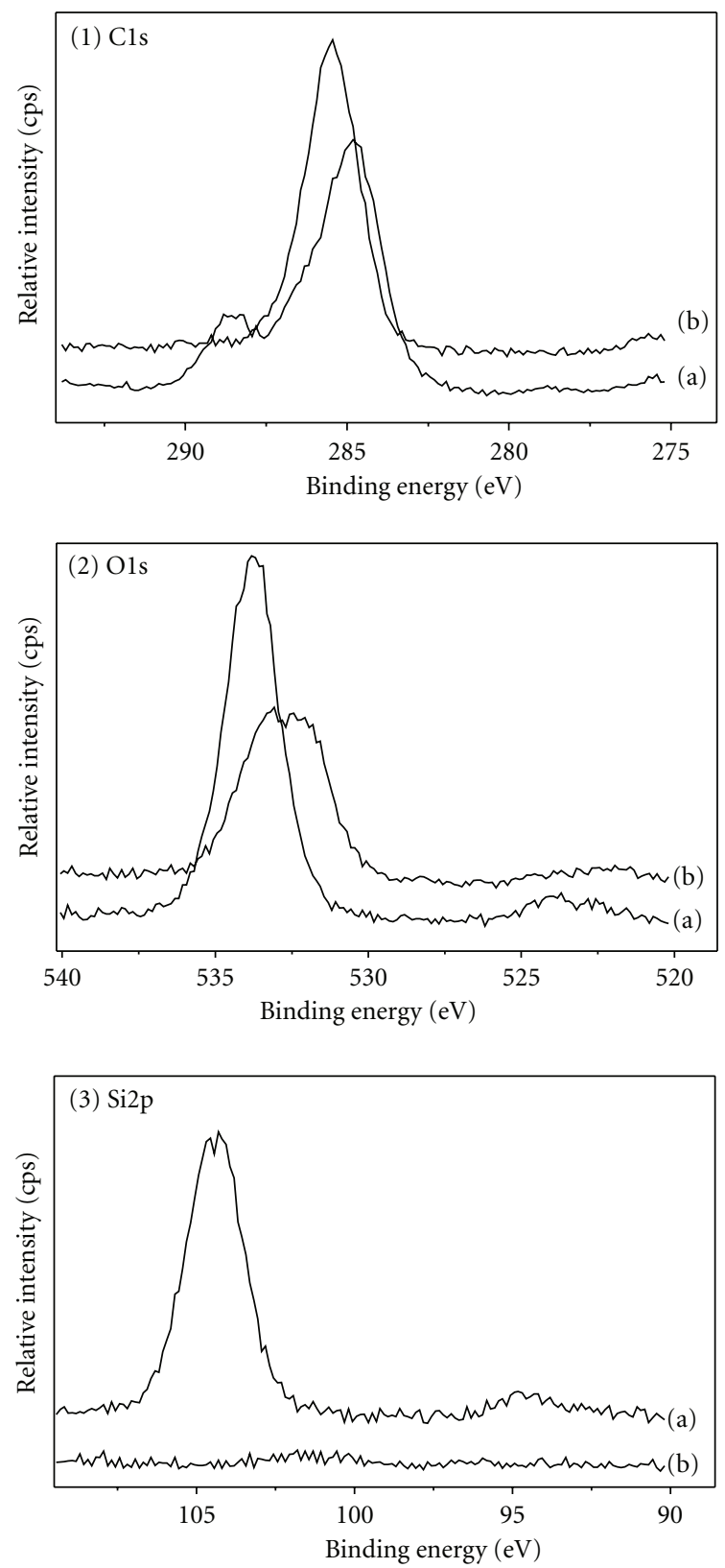

FIgURe 7: XPS analysis of C1s (1), O1s (2), and Si2p (3) spectra for (a) $\mathrm{SiO}_{2} @ M P T S$ particles and (b) $\mathrm{SiO}_{2} @ P M M A$ particles.

was acquired from Aldrich Chemical Co., Ltd. Hexaaquo iron(III) chloride, $\mathrm{FeCl}_{3} \cdot 6 \mathrm{H}_{2} \mathrm{O}$ (Across Organics, 99\%), was used as received. MMA (Fluka, 99\%) was distilled to an ice bath under reduced pressure in the presence of hydroquinone, washed twice with $5 \%$ $\mathrm{NaOH}$ in water, and dried over $\mathrm{CaCl}_{2}$. Cetyetrimethylammonium bromide (CTAB) was purchased from SigmaAldrich Chemical Co. (St. Louis, Mo). 2-hydroxy-4-(2hydroxyethoxy)-2-methyl-propiophenone (Irgacure 2959) was acquired from Sigma-Aldrich Co. All chemicals were of analytical grade and used without further purification. Doubly deionized water was used through all the processes.
2.2. Characterization. The FTIR measurements (Impact 400, Nicolet, Waltham, Mass) were carried out with the $\mathrm{KBr}$ pellet method. Thermogravimetric analysis (TGA) results were obtained with a TA Instrument 2050 thermogravimetric analyzer at a heating rate of $10^{\circ} \mathrm{C} / \mathrm{min}$ from 25 to $800^{\circ} \mathrm{C}$ under a nitrogen atmosphere. The microstructure of these hybrid nanocomposites was imaged using Hitachi H-600 equipment, and TEM samples of nanoparticles were prepared by casting one drop of a dilute colloid solution onto a carbon-coated copper grid. X-ray photoelectron spectra (XPS) were performed on a PHI-5702 instrument using $\mathrm{MgK} \alpha$ radiation with pass energy of $29.35 \mathrm{eV}$. The product particle size and its distribution were determined by dynamic light scattering (DLS) using a Malvern Zetasizer NanoZS apparatus with a laser of $660 \mathrm{~nm}$ wavelength at $25^{\circ} \mathrm{C}$. Before the analysis, the latexes were diluted with deionized water to minimize the particle-particle interactions.

\subsection{Synthesis}

2.3.1. Surface Modification of Silica Particles. Into a $250 \mathrm{~mL}$ dried round-bottom flask, $3.0 \mathrm{~g}$ nanosilica was ultrasound dispersed in $100 \mathrm{~mL}$ ethanol for $30 \mathrm{~min}$, then $2.5 \mathrm{~g}$ MPTS was added and ultrasound dispersed for $2 \mathrm{~h}$. The product was washed by centrifugations/redispersions three times in ethanol and dried in vacuum at room temperature for $24 \mathrm{~h}$. The grafting density of grafted vinyl group was determined by TGA and was calculated by [29]

Grafting density $\left(\mathrm{mol} / \mathrm{m}^{2}\right)$

$$
=\frac{\left(W_{60-730} /\left(100-W_{60-730}\right)\right) \times 100-W_{\text {silica }}}{\operatorname{MS}_{\text {spec }} \times 100} \times 10^{6},
$$

where $W_{60-730}$ is the weight loss from 60 to $730^{\circ} \mathrm{C}$ corresponding to the decomposition of the MPTS, $\mathrm{M}(\mathrm{g} / \mathrm{mol})$ is the molar mass of the degradable part of the grafted molecule (205 g/mol), Sspec $\left(\mathrm{m}^{2} / \mathrm{g}\right)$ and $W_{\text {silica }}$ are the specific surface area and the weight loss of silica determined before grafting, respectively.

2.3.2. Photopolymerization of PMMA on $\mathrm{SiO}_{2} @ M P T S$. $\mathrm{PMMA} / \mathrm{SiO}_{2}$ hybrid nanoparticles were synthesized through surface-grafted photopolymerization using a high-pressure Hg lamp as the UV light source. The compositions of emulsion are listed in Table 1. A pre-emulsification of $\mathrm{SiO}_{2}$ g-MPTS, MMA, CTAB, $\mathrm{FeCl}_{3} \cdot 6 \mathrm{H}_{2} \mathrm{O}$ (or Irgacure 2959), and water was carried out for $30 \mathrm{~min}$ in a flask with stirring at a speed of $400 \mathrm{rpm}$. The polymerization was conducted for $10 \mathrm{~min}$ in a reactor with a quartz cap as shown in Figure 1. The UV source used was a $1000 \mathrm{~W}$ high-pressure mercury lamp, and the light intensity was $20 \mathrm{~mW} / \mathrm{cm}^{2}$. During the UV irradiation, stirring and a nitrogen purge were maintained at ambient temperature. Hybrid particles were isolated via centrifugation at $4000 \mathrm{rpm}$. Then the particles were dispersed into $10 \mathrm{~mL}$ of tetrahydrofuran (THF) to remove PMMA absorbed on the particles. The solvent (THF) was replaced every eight hours. Particles were purified by centrifugation/redispersion for three times and then dried at 


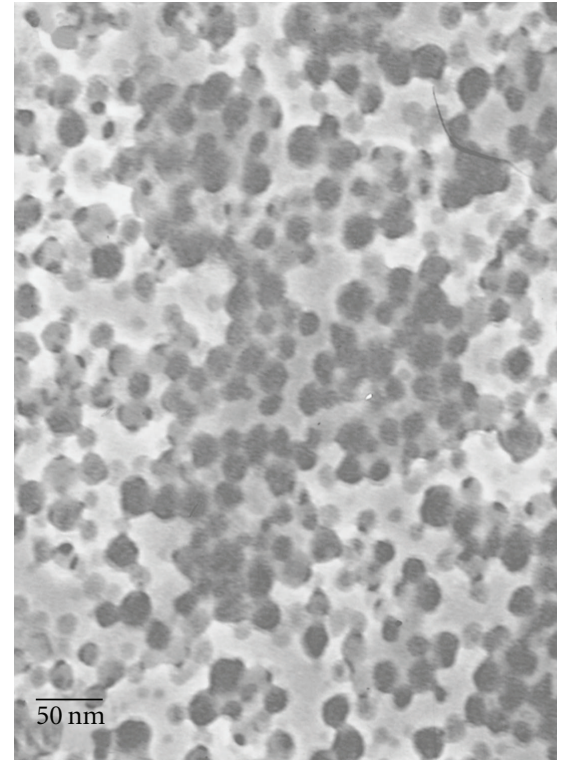

(a)

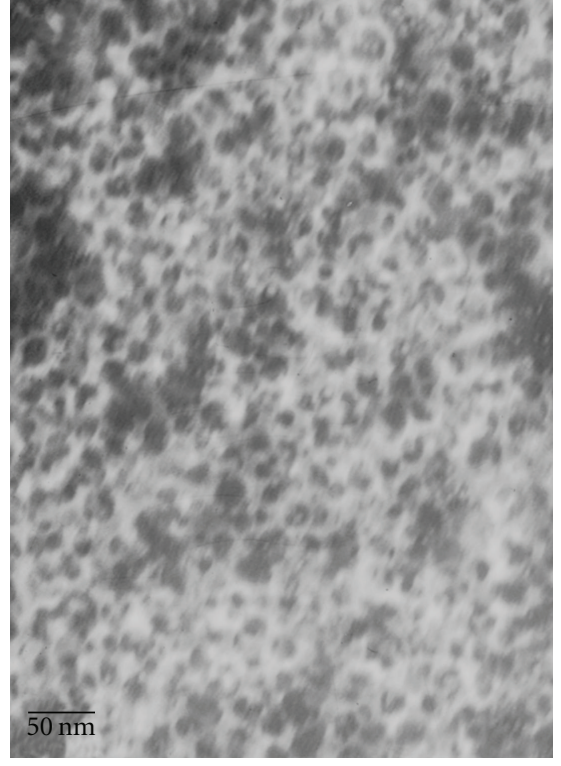

(b)

FIGURE 8: TEM images of (a) $\mathrm{SiO}_{2} @ P M M A$ particles (S-3) and (b) $\mathrm{SiO}_{2} @ P M M A$ particles (S-6) cast from dilute deionized water.

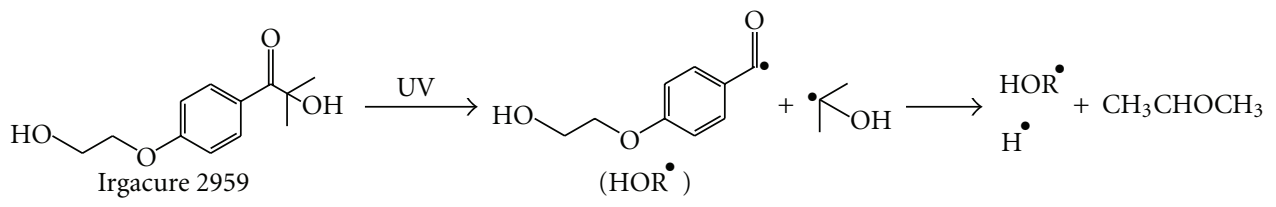<smiles>C=C(C)C(=O)OCCC[Si](O)(O)OC1CCC(CO)CC1</smiles>

SCHEme 2: The mechanisms of grafting polymerization initiated by Irgacure 2959.

room temperature under a vacuum to generate $\mathrm{PMMA} / \mathrm{SiO}_{2}$ hybrid nanoparticles.

The polymer grafting (\%) was determined by TGA and calculated by [30]

$$
\text { Polymer grafting }(\%)=\frac{\text { Organic composition } / g}{\text { Bare silica/g }} \times 100 \text {, }
$$

where the amount of organic composition (g) was calculated from the TGA weight loss from 150 to $700^{\circ} \mathrm{C}$ corresponding to the decomposition of PMMA. Bare silica ( $\mathrm{g}$ ) is the weight retention by TGA corresponding to the bare silica.

\section{Results and Discussions}

3.1. Analysis of FTIR. MPTS is well accepted as a suitable coupling agent for silica since the trimethoxysilyl groups can be hydrolyzed and condensed with the silanol groups at the surface of silica particles. Then, the nanosilica can be chemically modified by the reaction between PMMA and
MPTS. Figure 2 shows the FTIR spectra of $\mathrm{SiO}_{2}, \mathrm{SiO}_{2}$-gMPTS, and PMMA/SiO 2 . It can be seen that there is a very pronounced band appearing at $1108 \mathrm{~cm}^{-1}$, together with two less pronounced bands at 805 and $475 \mathrm{~cm}^{-1}$ in the spectrum of $\mathrm{SiO}_{2}$ as shown in Figure 2(a), which corresponds to the vibration absorption of $\mathrm{Si}-\mathrm{O}-\mathrm{Si}$ groups. The similar consequence appears in $\mathrm{SiO}_{2}$-g-MPTS in Figure 2(b). In the spectrum of $\mathrm{PMMA} / \mathrm{SiO}_{2}$ in Figure 2(c), there are peaks at 2952, 1732, and $1445 \mathrm{~cm}^{-1}$, which are assigned to $\mathrm{CH}, \mathrm{C}-\mathrm{O}$, and $\mathrm{CH}_{3}$ stretching vibration of PMMA, respectively. This result indicates that PMMA has been grafted onto the surface of $\mathrm{SiO}_{2}$ successfully.

3.2. Analysis by TGA. The thermogravimetric analysis (TGA) of bare silica, $\mathrm{SiO}_{2}$-g-MPTS, and $\mathrm{PMMA} / \mathrm{SiO}_{2}$ particles (S-3, S-4 and S-5) is shown in Figure 3. The high temperature required to decompose and evaporate the organic content of the modified silica particles demonstrates that the silane-coupling agent is strongly bound to the particle surface and one can expect a covalent bond [31]. Calculation 


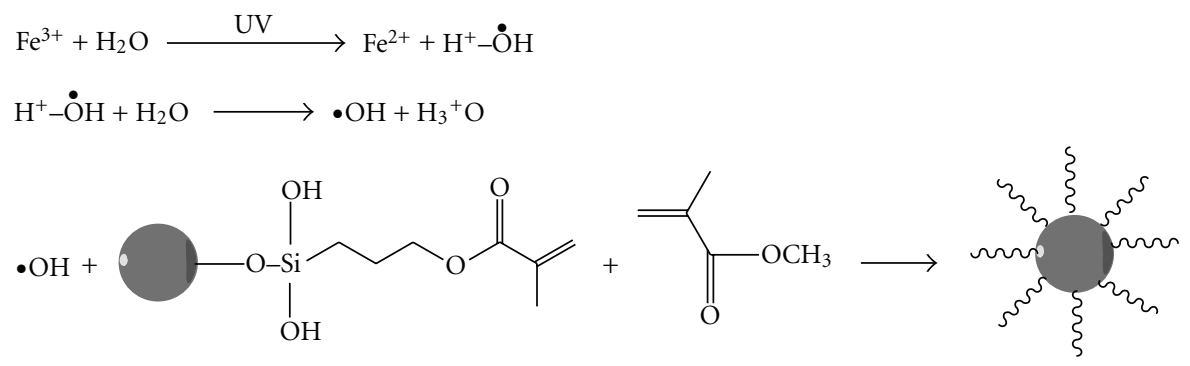

SCHEME 3: The mechanisms of grafting polymerization initiated by $\mathrm{FeCl}_{3}$.

based on TGA shows that the grafting density of grafted vinyl group is $0.92 \mu \mathrm{mol} / \mathrm{m}^{2}$ calculated from (1). The weight loss of bare silica below $200^{\circ} \mathrm{C}$ is $4.8 \%$ which is attributed to the physisorbed water and residual organic solvent. As for $\mathrm{PMMA} / \mathrm{SiO}_{2}$ particles, the beginning decomposition at $300^{\circ} \mathrm{C}$ corresponds to the decomposed temperature of PMMA covalently attached to nanosilica particles. The weight loss is increased from $9.0 \%$ to $89.2 \%$ when the $\mathrm{SiO}_{2}$ g-MPTS decreased from $0.50 \mathrm{~g}$ to $0.05 \mathrm{~g}$ and polymer grafting is increased from $13.5 \%$ to $98.0 \%$. These results show that the grafting degree increase resulted from the decreasing of the amount of the modified nanosilica.

3.3. Analysis by TEM. The morphologies of bare silica particles and functional silica particles modified by PMMA were investigated by TEM as shown in Figure 4. Figure 4(a) revealed that the bare silica particles with an average effective diameter of $20 \mathrm{~nm}$ are low dispersed and have a few aggregates. However, the size of $\mathrm{PMMA} / \mathrm{SiO}_{2}$ particles becomes larger than bare silica particles, and the dispersibility has been improved. With an increase of the concentration of $\mathrm{SiO}_{2}$-g-MPTS, the aggregates increased and the dispersibility got worse. Figures $4(\mathrm{~b}), 4(\mathrm{c})$, and $4(\mathrm{~d})$ show better dispersibility. In Figure 4(d), silica particles are completely encapsulated with PMMA that free silica can nearly not be observed and most of the hybrid nanoparticles appeared to be roughly spherically symmetric, although several larger nanoparticles appeared to be rather irregular. It can be concluded that PMMA can successfully encapsulate on silica once silica particles are modified by the double bonds. Besides, it exists a suitable $\mathrm{MMA} / \mathrm{SiO}_{2}$ ratio to prepare the core-shell structural $\mathrm{PMMA} / \mathrm{SiO}_{2}$ effectively.

3.4. Analysis by DLS. The sizes and distributions of bare silica particles and functional silica particles modified by PMMA have been investigated by DLS. Figure 5(a) shows that bare silica particles possess a narrow distribution with an average effective diameter of $20 \mathrm{~nm}$. This result agreed with the measure of TEM. The size of $\mathrm{PMMA} / \mathrm{SiO}_{2}$ in Figure 5(b) became bigger, and its size distribution ranged from 20 to $42 \mathrm{~nm}$ with one intensive peak at $32 \mathrm{~nm}$. From the result obtained, it can be assumed that PMMA has been grafted onto the surface of the silica nanoparticles successfully, and finally the core/shell structural nanosilica/polymethyl methacrylate composite latex has been formed.
3.5. Analysis by XPS. XPS measurement was used to further investigate the composition of the polymer on the silica surface. The wide scan XPS spectra of $\mathrm{SiO}_{2}$-g-MPTS (a) and $\mathrm{PMMA} / \mathrm{SiO}_{2}$ (b) are shown in Figure 6. We can see that the signals of Si2s $(160.9 \mathrm{eV})$ and Si2p (109.3 eV) in Figure 6(b) are much weaker than in Figure 6(a), which indicates that silica particles are basically encapsulated with PMMA. We can see from the wide scan XPS spectra of $\mathrm{PMMA} / \mathrm{SiO}_{2}$ as shown in Figure 7(1)(b) that the strongest signal appears, which corresponds to the aliphatic hydrocarbon $(\mathrm{C}-\mathrm{C} / \mathrm{C}-\mathrm{H}$, at a binding energy of $284.7 \mathrm{eV}$ ). It is larger than the $\mathrm{C} 1 \mathrm{~s}$ signal $(285.4 \mathrm{eV})$ intensity of $\mathrm{SiO}_{2}$-g-MPTS in Figure 7(1)(a). These signals indicate the presence of PMMA on the surface of silica. Figure 7(2) is the O1s XPS scan spectra; the O1s signal of MPTS-modified silica is due to the Si-O bond. As for O1s signal of the $\mathrm{PMMA} / \mathrm{SiO}_{2}$, the weak signal shifted to a binding energy of $533.8 \mathrm{eV}$, which corresponds to the carbonyl oxygen $(\mathrm{O}=\mathrm{C})$ of methyl methacrylate. Judging by combination of FTIR and XPS results, we can conclude that a functionalized surface has been generated by the method outlined in Scheme 1.

3.6. Analysis of Photoinitiation by Different Photoinitiator. Figure 8 shows the TEM images of $\mathrm{PMMA} / \mathrm{SiO}_{2}$ particles initiated by $\mathrm{FeCl}_{3}$ and Irgacure 2959. It is obvious that PMMA/SiO 2 particles initiated by $\mathrm{FeCl}_{3}$ presents better dispersion, uniformity, and higher encapsulated ratio. To make a further comparison between the $\mathrm{FeCl}_{3}$ and Irgacure 2959, different emulsions have been carried out and the results are presented in Table 2. As shown in Table 2, the two products have almost the same size. The particles initiated by $\mathrm{FeCl}_{3}$ have smaller polydispersity index (PDI) than initiated by Irgacure 2959. More significantly, the particles initiated by $\mathrm{FeCl}_{3}$ have higher monomer conversion and percent grafting. This proves that $\mathrm{FeCl}_{3}$ possesses higher efficiency than Irgacure 2959. The probable mechanisms of grafting polymerization initiated by Irgacure 2959 and $\mathrm{FeCl}_{3}$ are shown in Schemes 2 and 3, respectively. Consequently, we can conclude that $\mathrm{FeCl}_{3}$ has preferable property due to its well water-solubility, lower steric hindrance, and higher free radical production rate. Besides, small amounts of $\mathrm{FeCl}_{3}$ can promote the stability of emulsion.

\section{Conclusions}

A simple and convenient "grafting onto" strategy which involves two-step reaction to prepare $\mathrm{PMMA} / \mathrm{SiO}_{2}$ hybrid 
composites by UV irradiation is reported. Well-defined hybrid particles have been obtained via emulsion polymerization. The grafting density of the polymer can be adjusted in a wide range by simply controlling the introduction and the conversion of the double bonds on the silica surface. Especially, a small amount of $\mathrm{FeCl}_{3}$ can initiate the polymerization in $10 \mathrm{~min}$. It is highly efficient for the functionalization of nanosilica. Compared to the traditional photoinitiation initiated by Irgacure 2959, the products initiated by $\mathrm{FeCl}_{3}$ have higher monomer conversion, percent grafting, and better monodispersion.

\section{References}

[1] S. T. Milner, "Polymer brushes," Science, vol. 251, no. 4996, pp. 905-914, 1991.

[2] L. P. Wang, Y. P. Wang, R. M. Wang, and S. C. Zhang, "Preparation of polymer brushes on palygorskite surfaces via RAFT polymerization," Reactive and Functional Polymers, vol. 68, no. 2, pp. 643-648, 2008.

[3] A. M. Granville, S. G. Boyes, B. Akgun, M. D. Foster, and W. J. Brittain, "Thermo-responsive behavior of semi-fluorinated polymer brushes on flat substrates," Macromolecules, vol. 38, no. 8, pp. 3263-3270, 2005.

[4] Q. Zhou, X. Fan, C. Xia, J. Mays, and R. Advincula, "Living anionic surface initiated polymerization (SIP) of styrene clay surfaces," Chemistry of Materials, vol. 13, no. 8, pp. 2465-2467, 2001.

[5] X. Fan, C. Xia, T. Fulghum, M. K. Park, J. Locklin, and R. C. Advincula, "Polymer brushes grafted from clay nanoparticles adsorbed on a planar substrate by free radical surface-initiated polymerization," Langmuir, vol. 19, no. 3, pp. 916-923, 2003.

[6] D. A. Rider, J. I. L. Chen, J. C. Eloi et al., "Controlling the morphologies of organometallic block copolymers in the 3dimensional spatial confinement of colloidal and inverse colloidal crystals," Macromolecules, vol. 41, no. 6, pp. 2250-2259, 2008.

[7] W. Norde and D. Gags, "Interaction of bovine serum albumin and human blood plasma with PEO-tethered surfaces: influence of PEO chain length, grafting density, and temperature," Langmuir, vol. 20, no. 10, pp. 4162-4167, 2004.

[8] J. Lahiri, L. Isaacs, B. Grzybowski, J. D. Carbeck, and G. M. Whitesides, "Biospecific binding of carbonic anhydrase to mixed SAMs presenting benzenesulfonamide ligands: a model system for studying lateral steric effects," Langmuir, vol. 15, no. 21, pp. 7186-7198, 1999.

[9] A. Hucknall, S. Rangarajan, and A. Chilkoti, "In pursuit of zero: polymer brushes that resist the adsorption of proteins," Advanced Materials, vol. 21, no. 23, pp. 2441-2446, 2009.

[10] D. E. Kataoka and S. M. Troian, "Patterning liquid flow on the microscopic scale," Nature, vol. 402, no. 6763, pp. 794-797, 1999.

[11] B. Zhao and W. J. Brittain, "Polymer brushes: surface-immobilized macromolecules," Progress in Polymer Science, vol. 25, no. 5, pp. 677-710, 2000.

[12] J. W. Park and E. L. Thomas, "A surface-reactive rodcoil diblock copolymer: nano- and micropatterned polymer brushes," Journal of the American Chemical Society, vol. 124, no. 4, pp. 514-515, 2002.
[13] F. Gong, M. Feng, C. Zhao, S. Zhang, and M. Yang, “Thermal properties of poly(vinyl chloride)/montmorillonite nanocomposites," Polymer Degradation and Stability, vol. 84, no. 2, pp. 289-294, 2004.

[14] H. Zheng, Y. Zhang, Z. Peng, and Y. Zhang, "Influence of clay modification on the structure and mechanical properties of EPDM/montmorillonite nanocomposites," Polymer Testing, vol. 23, no. 2, pp. 217-223, 2004.

[15] J. Y. Lee and H. K. Lee, "Characterization of organobentonite used for polymer nanocomposites," Materials Chemistry and Physics, vol. 85, no. 2-3, pp. 410-415, 2004.

[16] F. Gong, M. Feng, C. Zhao, S. Zhang, and M. Yang, "Particle configuration and mechanical properties of poly(vinyl chloride)/montmorillonite nanocomposites via in situ suspension polymerization," Polymer Testing, vol. 23, no. 7, pp. 847-853, 2004.

[17] D. C. Tully, A. R. Trimble, J. M. J. Fréchet, K. Wilder, and C. F. Quate, "Synthesis and preparation of ionically bound dendrimer monolayers and application toward scanning probe lithography," Chemistry of Materials, vol. 11, no. 10, pp. 28922898, 1999.

[18] B. Zhao and W. J. Brittain, "Synthesis of polystyrene brushes on silicate substrates via carbocationic polymerization from self-assembled monolayers," Macromolecules, vol. 33, no. 2, pp. 342-348, 2000.

[19] Y. Tran and P. Auroy, "Synthesis of poly(styrene sulfonate) brushes," Journal of the American Chemical Society, vol. 123, no. 16, pp. 3644-3654, 2001.

[20] P. Mansky, Y. Liu, E. Huang, T. P. Russell, and C. Hawker, "Controlling polymer-surface interactions with random copolymer brushes," Science, vol. 275, no. 5305, pp. 1458-1460, 1997.

[21] O. Prucker and J. Rühe, "Synthesis of poly(styrene) monolayers attached to high surface area silica gels through selfassembled monolayers of azo initiators," Macromolecules, vol. 31, no. 3, pp. 592-601, 1998.

[22] O. Prucker and J. Rühe, "Mechanism of radical chain polymerizations initiated by azo compounds covalently bound to the surface of spherical particles," Macromolecules, vol. 31, no. 3, pp. 602-613, 1998.

[23] E. Bourgeat-Lami and J. Lang, "Encapsulation of inorganic particles by dispersion polymerization in polar media 1. Silica nanoparticles encapsulated by polystyrene," Journal of Colloid and Interface Science, vol. 197, no. 2, pp. 293-308, 1998.

[24] P. L. Kuo, N. J. Turro, C. M. Tseng, M. S. El-Aasser, and J. W. Vanderhoff, "Photoinitiated polymerization of styrene in microemulsions," Macromolecules, vol. 20, no. 6, pp. 12161221, 1987.

[25] S. Atik and J. K. Thomas, "Photoinduced reactions in polymerized microemulsions," Journal of the American Chemical Society, vol. 105, no. 14, pp. 4515-4519, 1983.

[26] N. J. Turro, M. F. Chow, C. J. Chung, and C. H. Tung, "Magnetic field and magnetic isotope effects on photoinduced emulsion polymerization," Journal of the American Chemical Society, vol. 105, no. 6, pp. 1572-1577, 1983.

[27] N. J. Turro and K. S. Arora, "Magnetic effects on photoinduced emulsion polymerization. Effects of lanthanide ion addition," Macromolecules, vol. 19, no. 1, pp. 42-46, 1986.

[28] M. G. Evans, M. Santappa, and N. Uri, "Photoinitiated free radical polymerizationof vinyl compounds in aqueous solution," Journal of Polymer Science, vol. 7, no. 23, pp. 243-260, 1951. 
[29] H. Zhang, J. Wang, L. Li, Y. Song, M. Zhao, and X. Jian, "Synthesis of liquid polysilisiquioxane resins and properties of cured films," Thin Solid Films, vol. 517, no. 2, pp. 857-862, 2008.

[30] Z. X. Guo and J. Yu, "Grafting of dendritic polyethers onto nanometre silica surface," Journal of Materials Chemistry, vol. 12, no. 3, pp. 468-472, 2002.

[31] A. Hartwig, M. Sebald, and M. Kleemeier, "Cross-linking of cationically polymerised epoxides by nanoparticles," Polymer, vol. 46, no. 7, pp. 2029-2039, 2005. 

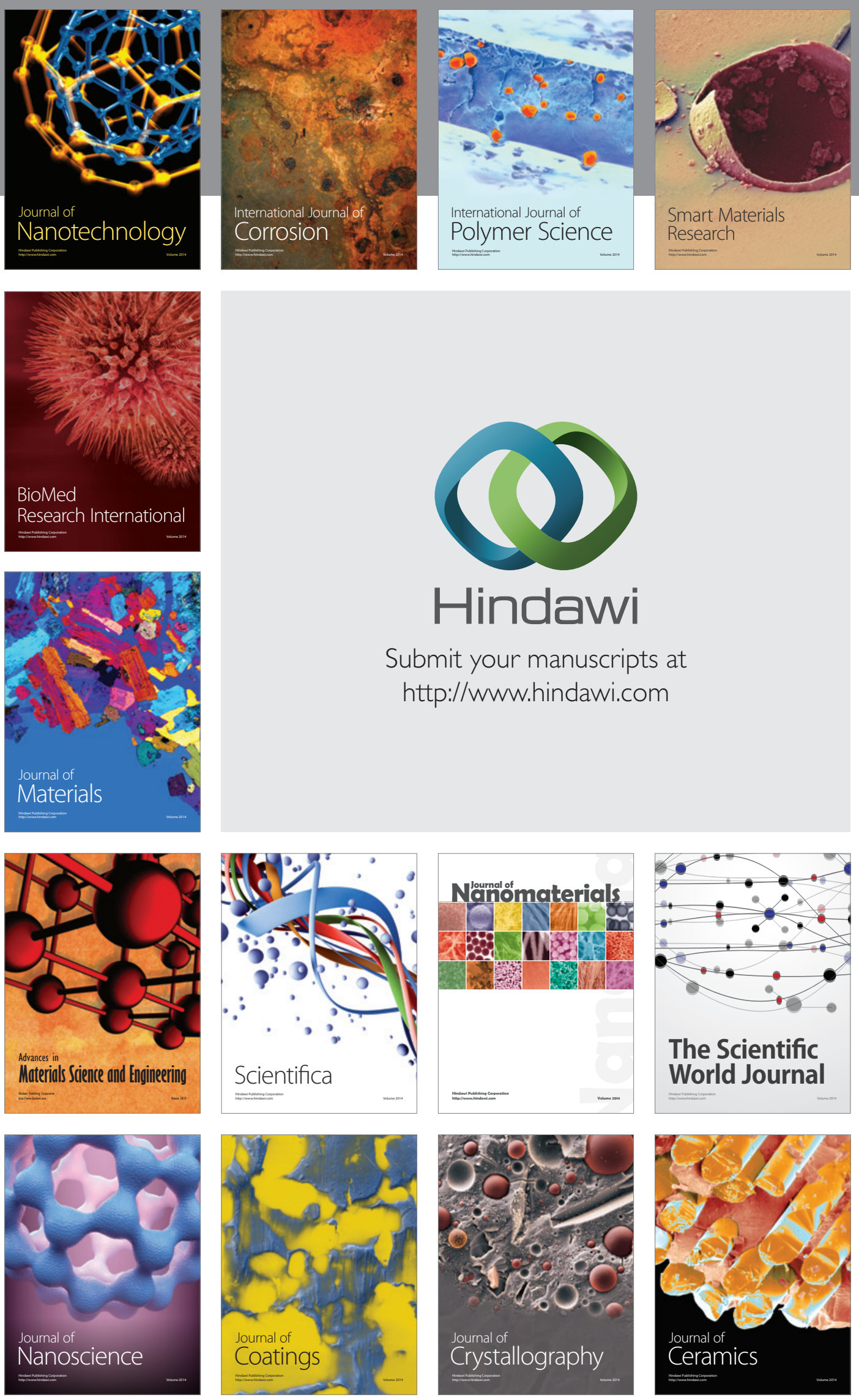

The Scientific World Journal

Submit your manuscripts at

http://www.hindawi.com

\section{World Journal}

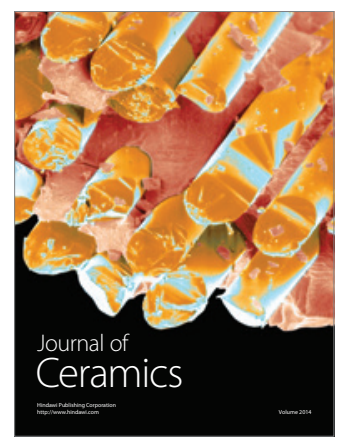

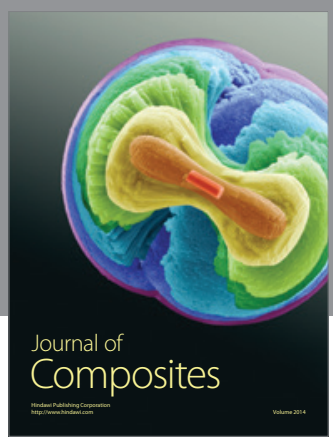
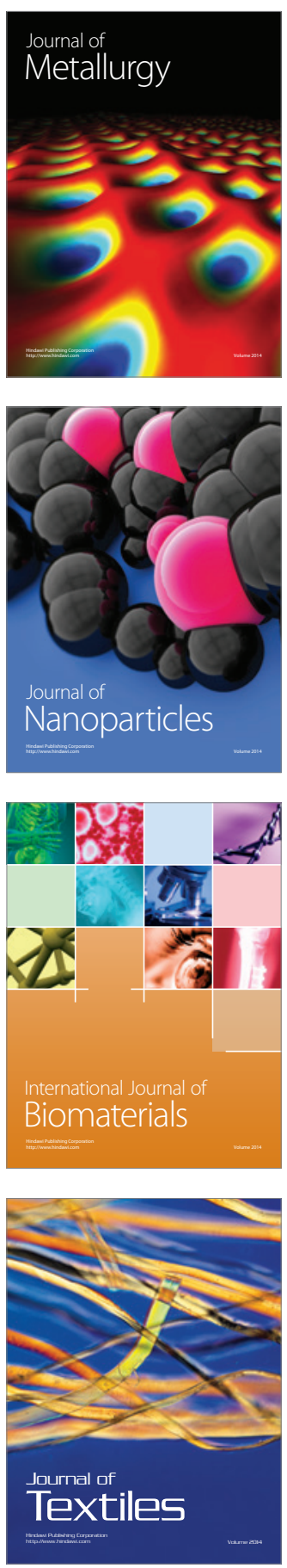